\title{
The EPICENTRE (ESPNIC Covid pEdiatric Neonatal Registry) initiative: background and protocol for the international SARS-CoV-2 infections registry
}

\author{
Daniele De Luca $^{1}$ (1) $\cdot$ Lucilla Rava $^{2} \cdot$ Simon Nadel $^{3} \cdot$ Pierre Tissieres $^{4} \cdot$ Orsola Gawronski $^{5} \cdot$ Elisabeth Perkins $^{6}$. \\ Giovanna Chidini ${ }^{7}$. David G. Tingay ${ }^{6}$
}

Received: 30 March 2020 / Revised: 11 May 2020 / Accepted: 13 May 2020 / Published online: 22 May 2020

(C) Springer-Verlag GmbH Germany, part of Springer Nature 2020

\begin{abstract}
The outbreak of SARS-CoV-2 is the worst healthcare emergency of this century, and its impact on pediatrics and neonatology is still largely unknown. The European Society for Pediatric and Neonatal Intensive Care (ESPNIC) launched the EPICENTRE (ESPNIC Covid pEdiatric Neonatal Registry) international, multicenter, and multidisciplinary initiative to study the epidemiology, clinical course, and outcomes of pediatric and neonatal SARS-CoV-2 infections. EPICENTRE background and aims are presented together with protocol details. EPICENTRE is open to centers all over the world, and this will allow to provide a pragmatic picture of the epidemic, with a particular attention to pediatric and neonatal critical care issues.

Conclusions: EPICENTRE will allow researchers to clarify the epidemiology, clinical presentation, and outcomes of pediatric and neonatal SARS-CoV-2 infection, refining its clinical management and hopefully providing new insights for clinicians.

\section{What is Known:}

- COVID19 is the new disease caused by SARS-CoV-2 infection and is spreading around the globe.

- Majority of data available about SARS-CoV-2 infections originates from adult patients.

What is New:

- EPICENTRE is the first international, multicenter, multidisciplinary, meta-data driven, hospital-based, online, prospective cohort registry dedicated to neonatal and pediatric SARS-CoV-2 infections.

- EPICENTRE will allow to understand epidemiology and physiopathology of COVID19.
\end{abstract}

Communicated by Nicole Ritz

Daniele De Luca

dm.deluca@icloud.com

Lucilla Rava

lucilla.rava@opbg.net

Simon Nadel

s.nadel@imperial.ac.uk

Pierre Tissieres

pierre.tissieres@aphp.fr

Orsola Gawronski

orsola.gawronski@opbg.net

Elisabeth Perkins

liz.perkins@mcri.edu.au

Giovanna Chidini

giovanna.chidini@policlinico.mi.it

David G. Tingay

David.Tingay@ rch.org.au
1 Division of Pediatrics and Neonatal Critical Care, Paris Saclay University Hospital-APHP \& Paris Saclay University, Paris, France

2 Unit of Clinical Epidemiology, "Bambino Gesu" Children Hospital-IRCCS, Rome, Italy

3 Paediatric Intensive Care Unit, Imperial College Healthcare NHS Trust, London, UK

4 Division of Pediatric Critical Care, Paris Saclay University Hospital-APHP \& Paris Saclay University, Paris, France

5 Continuing Education and Nursing Research Unit, "Bambino Gesu" Children Hospital-IRCCS, Rome, Italy

6 Neonatal Research, Murdoch Children's Research Institute, Melbourne, VIC, Australia

7 Pediatric Intensive Care Unit, Department of Anesthesia, Intensive Care and Emergency, Fondazione IRCCS Ca' Granda Ospedale Maggiore Policlinico, Milan, Italy 
Keywords Children $\cdot$ Neonate $\cdot$ Coronavirus $\cdot$ Database $\cdot$ Outbreak $\cdot$ Pandemic

$\begin{array}{ll}\text { Abbreviations } & \\ \text { ARDS } & \text { acute respiratory distress syndrome } \\ \text { COVID19 } & \text { Coronavirus disease-19 } \\ \text { EPICENTRE } & \text { ESPNIC Covid pEdiatric Neonatal Registry } \\ \text { ESPNIC } & \begin{array}{l}\text { European Society for Pediatric and Neonatal } \\ \text { Intensive Care }\end{array} \\ \text { NARDS } & \text { neonatal acute respiratory distress syndrome } \\ \text { PARDS } & \text { pediatric acute respiratory distress syndrome } \\ \text { RT-PCR } & \text { real time-polymerase chain reaction } \\ \text { WHO } & \text { World Health Organization. }\end{array}$

\section{Background}

Since December 2019, the outbreak of a novel $\beta$-coronavirus (SARS-CoV-2) shocked the world. The new infection has been officially recognized as pandemic by the World Health Organization (WHO) on March 11, 2020 (https://www.who. $\mathrm{int} / \mathrm{dg} / \mathrm{speeches/detail/who-director-general-s-opening-}$ remarks-at-the-media-briefing-on-covid-19\%2D\%2D-11march-2020).

The disease caused by SARS-CoV-2 infection is called COVID19 and seems to be characterized mainly by upper airway inflammation, which can progress into an interstitial pneumonia and eventually to something similar to the acute respiratory distress syndrome (ARDS) in the severest cases [1]. Renal [2] and myocardial [3] impairments have also been reported in a minority of cases, while a possible viral neurotropism has been hypothesized [4]. COVID19 seems to affect especially adults, and the disease severity seems to increase with advancing age and the number of comorbidities (https://www.cdc.gov/mmwr/volumes/69/wr/mm6912e2. htm?s_cid=mm6912e2_w) [5].

COVID19 seems relatively less frequent and more benign in pediatric populations, although severe cases have been reported and this appearance may be biased by our incomplete knowledge of this new disease [6-8]. Anyhow, the background behind the incidence and severity of COVID19 in children is not well understood. Children are usually more often affected by respiratory viral infections because of their immature immunocompetence, but this does not seem to apply to SARS-CoV-2. Several hypotheses have been formulated to explain this phenomenon. For instance, children might have a cross-immunity towards other coronaviruses with similarity to SARS-CoV-2. Also, the severest forms of COVID19 seen in some adult patients might be due to an uncontrolled, chaotic inflammatory host response (the so-called cytokine storm), more than to the direct viral cytopathic effect, and children may be less prone to develop this excessive host response [5-8].
These physiopathological hypotheses have led to a variety of different therapeutic strategies being proposed, based on pharmacological agents supposed to have antiviral activity with varying degrees of preclinical evidence [9] or on molecules able to modulate the inflammatory response [10-12]. These strategies have been used both for compassionate care and within a clinical trial framework, but we still do not know the best strategies to choose, the optimal time frame for that particular therapy and the patients who might be more responsive. However, these are only some general "unknown" on the topic and we are going to detail those specifically related to pediatric populations.

\section{Pediatric issues related to SARS-COV-2 infection}

In addition to the issues described above, there are additional unknowns in pediatrics. There is very little published pediatric experience about use of experimental therapies for COVID19; therefore, we are not able to evaluate their risk/benefit ratio in this population. Related to that, we are not sure about the physiopathological mechanisms behind the relatively low incidence and severity of COVID19 in children. The available literature about pediatric COVID19 is mainly coming from China. A recent Chinese series of more than two thousand children showed that severe forms of COVID19 are more frequent in infants aged less than 12 months rather than in older children [13]. Consistently, a recent case report described a 55-day-old infant suffering from multiorgan failure due to severe COVID19 [14]. Some case series, also published outside of China, described the same age distribution and confirmed that (1) children with pre-existing comorbidities may present severe forms of the disease and (2) children and adults mostly share signs and symptoms at COVID19 onset [6-8, 14-16]. Other reports have shown that neonates born to mothers with COVID19 have clinical features compatible with those of the disease in adults and older children (such as dyspnea, fever, thrombocytopenia, abnormal liver function, vomiting) $[17,18]$. A small case series suggests that children with more severe COVID19 might experience a cytokine storm similar to adult patients [19]. Even when pediatric COVID19 is just a mild disease, children may spread the virus for longer periods than adults, particularly through the oro-fecal route [20]. Italians clinicians were exposed to a significant pressure due to the epidemiological situation and proposed an algorithm for patients' isolation and de-isolation based on their age and clinical severity, although this is dictated by the public health emergency and is not evidencebased [21]. Furthermore, several alerts have been launched 
on the media and from some national scientific societies regarding an apparent surge in the incidence of myocarditis and Kawasaki disease and one case has been recently reported [22]. The situation is extremely evolutive, and the link between SARS-CoV-2 infection and these clinical manifestations deserves urgent investigation. Thus, many clinical questions remain unanswered: a better understanding of COVID19 physiopathology might eventually be useful also for the management of adult patients.

Furthermore, newborn infants represent a particular population. Pregnant women may be infected by SARS-CoV-2 and eventually develop COVID19 at different times during their pregnancy [23]. Available data seem to suggest that COVID19 is less severe during pregnancy, and this could be linked to the relative maternal immunodeficiency which leads to "tolerance" of the fetus, and which might prevent the cytokine storm and the development of severe infection and respiratory failure [23]. However, examples of pregnant women with ARDS needing mechanical ventilation have been observed (De Luca, Personal communications March/April 2020), although not yet fully described in scientific publications. Vertical transmission of SARS-CoV-2 seems uncommon but possible. A first case series seemed to exclude it [24]; however, other reports have demonstrated (1) neonatal complications and clinical symptoms similar to those of COVID19 in adults [17]; (2) neonatal infection by detecting IgM antiSARS-CoV-2 antibodies or viral genome by real timepolymerase chain reaction (RT-PCR) [25-27]; and (3) the existence of neonatal congenital pneumonia in neonates positive for SARS-CoV-2 who were born to mothers with COVID19 [28]. Some other cases of neonatal infection have been reported by the media in Italy (and then in other Countries), although it is not clear if these babies were infected vertically or by environmental exposure (https://www.cdc. gov $/ \mathrm{mmwr} /$ volumes $/ 69 / \mathrm{wr} / \mathrm{mm} 6912 \mathrm{e} 2 . \mathrm{htm}$ ?s_cid= mm6912e2_w)

It is unknown whether breastfeeding is a safe procedure. In fact, only six breast milk samples have been analyzed with RT-PCR so far, and been shown to be negative for COVID19 [24]. RT-PCR false negative may account for up to $30 \%$ of tests [29], and this, together with the very small sample size, does not allow us to draw any conclusion. The Chinese Center for Disease Control [30] and experts' consensus [31] recommend against breastfeeding and advise separation of the mother and her baby for 14 days. The United States Centers for Disease Control and Prevention also states that clinicians should consider temporarily separating (e.g., separate rooms) the mother from her baby until the mother's transmissionbased precautions are discontinued, and to use expressed breast milk for bottle feeding, rather than direct breastfeeding (https://www.cdc.gov/mmwr/volumes/69/wr/mm6912e2. htm? cid=mm6912e 2 w). The American Academy of Pediatrics is considering these issues, but has not yet released an official position (https://www.aappublications. org/news/2020/03/12/coronavirus031220), while a number of other scientific societies and bodies more optimistically recommend to breastfeed. Other $\beta$-coronaviruses, and particularly the Middle East Respiratory Syndrome coronavirus, which shares more than $50 \%$ of genetic sequence and several biological characteristics with SARSCoV-2 [32], are known to be transmitted through breast milk in animals [33-36]. We clearly need more data, based on welldesigned, large studies analyzing breast milk samples obtained in different phases of COVID19 disease to clarify if the virus is present and transmittable and if there are any antibodies secreted in the milk.

Last but not least, we need to increase our knowledge in terms of laboratory findings. Unlike in adults, a consistent pattern of laboratory anomalies has yet to be observed in children with confirmed COVID19: the available reports have shown conflicting data in terms of blood cell count, inflammatory markers, and other biochemical parameters [37]. The specific accuracy of RT-PCR in children is not known, and we need to clarify the role of other tests. The detection of antibodies would be particularly useful to screen and diagnose the vertical transmission from mother to the fetus and the neonate, but also to study the immunity and eventually understand better the biological mechanism behind pediatric COVID19. Recently, several kits have been designed to detect antibodies against SARS-CoV-2 and some of them also represent pointof-care assays with rapid turnaround [38]. While these tools create hope to speed up the diagnosis and provide an earlier treatment, their accuracy and suitability in pediatrics urgently need to be investigated.

\section{The particular case of pediatric and neonatal critical care}

Out of the few data described so far, we do not know much about the real need for critical care of pediatric COVID19 patients. Theoretically, neonates and children might have severe forms of COVID19 needing intensive care support of vital functions, and the case series described above demonstrate that this scenario does occur, but is infrequent. There is likely to be a publication bias due to the extreme work overload of clinicians who are not able to publish their experience: ARDS and other organ failures due to COVID19 in children have been observed (Tissieres, personal communication March/April 2020), but these remain unpublished personal observations. ARDS in children and in neonates has been recently defined using age-specific definitions which also allow us to stratify their clinical severity [39-41]. These definitions are useful for clinicians, at least for the diagnosis and clinical follow-up of these patients; however, their critical care is essentially based on the experience accumulated in the field 
of COVID19 adult care. The European Society for Intensive Care Medicine and the European Society for Pediatric and Neonatal Intensive Care (ESPNIC) have organized serial webinars to share this experience (https://www.esicm.org/ resources/coronavirus-public-health-emergency/\# WEBINARS, https://espnic-online.org/COVID-19-Outbreak/ ESPNIC-Webinars). The use of steroids or other immunomodulating agents to attenuate the cytokine storm in severe COVID19 infection may be considered, based on recent encouraging results obtained in adults [42]. Similarly, there have been announcements of trial results showing encouraging results for antiviral therapy with remdesivir (https://www.niaid.nih.gov/news-events/nih-clinical-trialshows-remdesivir-accelerates-recovery-advanced-covid-19) and for tocilizumab to modulate the host immune response in adults (https://www.aphp.fr/contenu/tocilizumab-improvessignificantly-clinical-outcomes-patients-moderate-or-severecovid-19).

Beside these experiences from adult intensivists, the clinical management should be based on European and American expert consensus [43, 44]. However, even within these consensus documents there are many open questions and grey areas. Moreover, there are also doubts about issues specifically related to COVID19 critical care, such as the safety to healthcare workers and clinical efficacy of non-invasive ventilation and heated humidified high flow nasal cannula, or the timing to start invasive ventilation or extra-corporeal life support. The use of ancillary respiratory therapy (e.g., surfactant, nitric oxide, other pulmonary vasodilators) is also unclear and requires a case-by-case evaluation based on clinical and physiological details. Thus, there are several open questions for ARDS in children and in neonates in general, but even more for those induced by COVID19, given the lack of experience about this disease. COVID19 has the merit to have heightened the attention on these issues and hopefully will push research to address these unmet clinical needs.

Finally, COVID19 may have indirect consequences on neonatal and pediatric critical care, as many neonatal and pediatric intensive care units around the world have been converted to COVID19 intensive care units to take care of critically ill adult patients. We do not know yet what is the suitability and usefulness of these initiatives. However, certainly the need to support adult critical care clinicians and to gain new competences in a relatively short time, together with the lack of critical care resources, may open important ethical dilemmas. These are currently being discussed within the ESPNIC Section on Ethics. This is surely only one of many ethical problems related to pediatrics during the COVID19 era as many others may arise, from resource allocation, to patients' triage and to the recent call for an end to the US President Donald Trump's ban on fetal-tissue research (https://www.nature.com/articles/d41586-020-00154-w).

\section{The EPICENTRE protocol}

As described above, the complexity of issues related to COVID19 in pediatrics and neonatology is clear. Because of this and the wide diffusion of the outbreak, it is evident that we need special initiatives to increase our knowledge in the field, to answer the unmet clinical and research needs and to maximize our response. The numerical impact of SARS-CoV-2 in children and neonates is lower than in adults, as pediatric COVID19 disease seems to account for only $1-5 \%$ of all described cases [45]. Thus, any project in this area should have a multicenter design in order to achieve a sufficient statistical power and describe accurately and pragmatically the clinical issues during this medical catastrophe.

In line with these considerations, ESPNIC decided to launch a multicenter, multidisciplinary, meta-data driven, hospital-based, online, prospective cohort registry dedicated to neonatal and pediatric SARS-CoV-2 infections and called EPICENTRE (ESPNIC Covid pEdiatric Neonatal Registry).

EPICENTRE is an international effort deployed during the pandemic, starting from Europe as it has been severely affected, but rapidly extended to non-European countries. The Registry is a multidisciplinary initiative which will collect data of both medical and nursing interest. EPICENTRE is designed to prospectively collect clinical data of hospitalized neonates and children infected by SARS-CoV-2, as well as that of neonates born to infected mothers. The data are collected through a dedicated database, customized using REDCap ${ }^{\circledR}$ software and hosted at the Murdoch Children Research Institute in Melbourne MCRI (Vic, Australia); EPICENTRE will receive institutional review board approval by the MCRI Ethical Committee, and local ethical approvals if these are needed according to national/local regulations. Data stored in the registry is non-identified, with only local investigators in each center holding re-identifiable codes in accordance with Australian, European, and/or privacy and data storing regulations. If required within a site, parents or guardians will be asked for informed consent to participate.

The initiative has received endorsement by the ESPNIC Executive Committee according to internal procedures. EPICENTRE has a Scientific Committee that will scientifically supervise the study and is composed of international experts in pediatric and neonatal critical care, as follows:

- Daniele De Luca (Paris, France), David Tingay (Melbourne, Vic, Australia) - Co-Chairs

- Elizabeth Perkins (Database coordinator)

For the Pediatric cohort:

- Giovanna Chidini (Milan, Italy)

- Etienne Javouhey (Lyon, France)

- Martin Kneyber (Groningen, The Netherlands) 
- Simon Nadel (London, UK)

- Pierre Tissieres (Paris, France)

For the neonatal cohort:

- Olivier Danhaive (Bruxelles, Belgium)

- Yasser Elsayed (Winnipeg - MA, Canada)

- Francesco Raimondi (Naples, Italy)

- Peter Rimensberger (Geneve, Switzerland)

- Howard Stein (Toledo, OH, USA)

Statistical analysis will be performed by the two project chairs with the technical assistance of Elizabeth Perkins who will manage the REDCap ${ }^{\circledR}$ database. EPICENTRE design follows the Strengthening the Reporting of Observational Studies in Epidemiology Statement [46]. EPICENTRE has no funding and no sponsor; it has been conceived and developed spontaneously during working time. Authors have no conflict of interest or financial relationship related to this initiative to declare. ESPNIC secretariat provided technical assistance and videoconference tools for free.

EPICENTRE has been rapidly developed through contacts with several national scientific societies or local networks in order to harmonize items to be collected and increase the chance to merge data with local registries. Examples of data that might be eventually merged are the patients' main outcomes, side effects of antiviral therapies or the incidence of vertical infection and transmission route. EPICENTRE works as an initiative linking several others and will be useful to answer several research questions.

EPICENTRE looks to register demographics, clinical, imaging, and laboratory data of children infected by SARS$\mathrm{CoV}-2$, provided that they have been hospitalized and require critical care for any reason. Moreover, EPICENTRE also collects data of neonates born to mothers infected by SARS$\mathrm{CoV}-2$, irrespective of their clinical status, and of neonates hospitalized for SARS-CoV-2 infection in any neonatal unit. For practical and academic purposes, EPICENTRE is subdivided in two similar but distinct data sets: one for neonates (i.e., for infections occurring in the first 30 days of life and for neonates born to infected mothers) and one for children (i.e., for infections occurring beyond the first 30 days of life). All the data items represent common data observed or measured in clinical care and does not require any particular diagnostic procedure. The clinical care is provided according to local protocols, and there will be no changes solely for study purposes. When a particular item is unavailable, the related field will be left empty. EPICENTRE has no exclusion criteria since, in the current situation, it is important to collect data from children with pre-existing comorbidities, malformations, or other conditions. Each participating hospital shall have one contact physician who is responsible of data check and input.
In details, EPICENTRE aims to

1. Describe the general epidemiology and outcomes of neonatal and pediatric SARS-CoV-2 infections

2. Investigate if SARS-CoV-2 can be transmitted through breast milk and if mother/neonate separation is beneficial or useful

3. Describe the clinical course, need for respiratory, and critical care of severe COVID19 in neonates and children

4. Describe the use and side effects of candidate antiviral or other adjunctive therapies for neonatal and pediatric COVID19 infection

5. Investigate the value of clinical, laboratory, and imaging findings to predict the clinical severity and other outcomes in the enrolled population

Report forms for both registry sides are available upon request and any additional information may be obtained by writing to: epicentre@mcri.edu.au.

It is unfeasible to calculate an ideal sample size to answer these questions, as the current situation is novel and unpredictable. We cannot foresee for how long EPICENTRE recruitment will last, as we do not know the outbreak duration; thus, EPICENTRE is prepared to be a long-lasting project and interim analyses will be performed according to the quickly evolving situation and the knowledge that will be accumulated.

The EPICENTRE initiative has been disseminated through ESPNIC channels and also in several virtual meetings between neonatologists and pediatric intensivists all over the world. Collaborating national scientific societies and networks also contributed to advertise EPICENTRE, and thanks to this effort, about 100 centers around the world have joined or expressed willingness to join the network as per May 3, 2020.

Similar to all epidemiological and observational studies, EPICENTRE will have some limitations. For example, the design aims to be comprehensive and pragmatic, but some geographical areas may not be covered by EPICENTRE network as the project may not be feasible for technical or administrative reasons. To mitigate this, we have corresponded with other local/national registries to ensure data fields match as closely as possible. This will allow the potential to merge data later to answer specific research questions. There needs to be a balance between detail of data included, such as physiological data, biosamples, and public health data linkage, and the ability of healthcare systems to manage accurate data entry during a pandemic. We have attempted to find a practical and pragmatic solution to these conflicting needs but acknowledge that this comes at the expense of scope. In most regions, local authorities have established large-scale data linkage, but without the detail on critical care needs in children. If possible, we may be able to utilize these resources in the future. Finally, the need to be hospitalized in an intensive/critical care setting for 
children beyond neonatal age may be dependent on the local setting/protocols and availability of critical care facilities. However, this is a common problem of pragmatic study design and is generally appropriate when refinements of current care are investigated [47].

EPICENTRE will result in several presentations or publications which will have group authorships, in collaboration with local/national registries (if any), for each of the abovedescribed research questions. Data will be presented at the ESPNIC congresses and in international journals in the field of pediatrics/neonatology and/or critical care, as well as disseminated through ESPNIC social media channels, once officially published.

Time is critical, and we invite all interested clinicians to join EPICENTRE. This will be useful for the clinical care of our COVID19 neonatal and pediatric patients and hopefully to help clarify some issues of wider interest for all clinicians.

Acknowledgments The authors are grateful to the ESPNIC Office for the technical support.

Authors' contributions DDL and DT conceived the project, wrote the manuscript draft, and managed all the links with participating centers.

EP built up the database and the data collection instruments and predisposed the statistical analysis.

SN, PT, LR, and OG helped in building up the data collection tool and in the link with the participating centers.

GC helped to draw the project, supervised the development, and managed the link with some participating centers.

All authors critically reviewed the manuscript for important intellectual content.

Funding information The Murdoch Children's Research Institute is supported by the Victorian Government Operational Infrastructure Support Program (Melbourne, Australia). DGT is supported by a National Health and Medical Research Council Clinical Career Development Fellowship (Grant ID 1053889). There is no specific funding source for the EPICENTRE project.

\section{Compliance with ethical statements}

Conflict of interest The authors declare that they have no conflict of interest.

Ethical approval Currently under review by the Institutional review Board of the Murdoch Children Research Institute (Project ID\#64264, submitted May 4, 2020, Melbourne, Vic, Australia). Other local ethical approvals will be obtained in each center if required by local regulations.

Informed consent Informed consent will be obtained from individual participants included in the study, according to local regulations.

\section{References}

1. Rodriguez-Morales AJ, Cardona-Ospina JA, Gutiérrez-Ocampo E, Villamizar-Peña R, Holguin-Rivera Y, Escalera-Antezana JP, Alvarado-Arnez LE, Bonilla-Aldana DK, Franco-Paredes C,
Henao-Martinez AF, Paniz-Mondolfi A, Lagos-Grisales GJ, Ramírez-Vallejo E, Suárez JA, Zambrano LI, Villamil-Gómez WE, Balbin-Ramon GJ, Rabaan AA, Harapan H, Dhama K, Nishiura H, Kataoka H, Ahmad T, Sah R (2020) Clinical, laboratory and imaging features of COVID-19: a systematic review and meta-analysis. Travel Med Infect Dis:101623. https://doi.org/10. 1016/j.tmaid.2020.101623

2. Perico L, Benigni A, Remuzzi G (2020) Should COVID-19 concern nephrologists? Why and to what extent? Emerg Impasse Angiotensin Blockade Nephron:1-9. https://doi.org/10.1159/ 000507305

3. Zhou F, Yu T, Du R et al (2020) Clinical course and risk factors for mortality of adult inpatients with COVID-19 in Wuhan, China: a retrospective cohort study. The Lancet 395:1054-1062. https://doi. org/10.1016/S0140-6736(20)30566-3

4. Baig AM, Khaleeq A, Ali U, Syeda H (2020) Evidence of the COVID-19 virus targeting the CNS: tissue distribution, host-virus interaction, and proposed neurotropic mechanisms. ACS Chem Neurosci 11:995-998. https://doi.org/10.1021/acschemneuro. 0c00122

5. Yang J, Zheng Y, Gou X, Pu K, Chen Z, Guo Q, Ji R, Wang H, Wang Y, Zhou Y (2020) Prevalence of comorbidities in the novel Wuhan coronavirus (COVID-19) infection: a systematic review and meta-analysis. Int J Infect Dis 94:91-95. https://doi.org/10. 1016/j.jijid.2020.03.017

6. Parri N, Lenge M, Buonsenso D, Coronavirus Infection in Pediatric Emergency Departments (CONFIDENCE) Research Group (2020) Children with Covid-19 in pediatric emergency departments in Italy. N Engl J Med. https://doi.org/10.1056/NEJMc2007617

7. Castagnoli R, Votto M, Licari A, Brambilla I, Bruno R, Perlini S, Rovida F, Baldanti F, Marseglia GL (2020) Severe acute respiratory syndrome coronavirus 2 (SARS-CoV-2) infection in children and adolescents: a systematic review. JAMA Pediatr. https://doi.org/10. 1001/jamapediatrics.2020.1467

8. Tagarro A, Epalza C, Santos M, Sanz-Santaeufemia FJ, Otheo E, Moraleda C, Calvo C (2020) Screening and severity of coronavirus disease 2019 (COVID-19) in children in Madrid, Spain. JAMA Pediatr. https://doi.org/10.1001/jamapediatrics.2020.1346

9. Zhang L, Liu Y (2020) Potential interventions for novel coronavirus in China: a systematic review. J Med Virol 92:479-490. https:// doi.org/10.1002/jmv.25707

10. Mehta P, McAuley DF, Brown M et al (2020) COVID-19: consider cytokine storm syndromes and immunosuppression. Lancet 395: 1033-1034. https://doi.org/10.1016/S0140-6736(20)30628-0

11. Stebbing J, Phelan A, Griffin I, Tucker C, Oechsle O, Smith D, Richardson P (2020) COVID-19: combining antiviral and antiinflammatory treatments. Lancet Infect Dis 20:400-402. https:// doi.org/10.1016/S1473-3099(20)30132-8

12. Arabi YM, Fowler R, Hayden FG (2020) Critical care management of adults with community-acquired severe respiratory viral infection. Intensive Care Med 46:315-328. https://doi.org/10.1007/ s00134-020-05943-5

13. Dong Y, Mo X, Hu Y, Qi X, Jiang F, Jiang Z, Tong S (2020) Epidemiological characteristics of 2143 pediatric patients with 2019, Coronavirus Disease in China. Pediatrics:e20200702. https://doi.org/10.1542/peds.2020-0702

14. Cui Y, Tian M, Huang D, Wang X, Huang Y, Fan L, Wang L, Chen Y, Liu W, Zhang K, Wu Y, Yang Z, Tao J, Feng J, Liu K, Ye X, Wang R, Zhang X, Zha Y (2020) A 55-day-old female infant infected with 2019 novel coronavirus disease: presenting with pneumonia, liver injury, and heart damage. J Infect Dis 221:1775-1781. https://doi.org/10.1093/infdis/jiaa113

15. Zheng F, Liao C, Fan Q, Chen HB, Zhao XG, Xie ZG, Li XL, Chen CX, Lu XX, Liu ZS, Lu W, Chen CB, Jiao R, Zhang AM, Wang JT, Ding XW, Zeng YG, Cheng LP, Huang QF, Wu J, Luo XC, Wang ZJ, Zhong YY, Bai Y, Wu XY, Jin RM (2020) Clinical 
characteristics of children with coronavirus disease 2019 in Hubei, China. Curr Med Sci 40:275-280. https://doi.org/10.1007/s11596020-2172-6

16. Lu X, Zhang L, Du H et al (2020) SARS-CoV-2 infection in children. N Engl J Med 382:1663-1665. https://doi.org/10.1056/ NEJMc2005073

17. Zhu H, Wang L, Fang C, Peng S, Zhang L, Chang G, Xia S, Zhou W (2020) Clinical analysis of 10 neonates born to mothers with 2019-nCoV pneumonia. Transl Pediatr 9:51-60. https://doi.org/ $10.21037 /$ tp.2020.02.06

18. Wang J, Wang D, Chen G-C, Tao XW, Zeng LK (2020) SARSCoV-2 infection with gastrointestinal symptoms as the first manifestation in a neonate. Zhongguo Dang Dai Er Ke Za Zhi 22:211214

19. Sun D, Li H, Lu X-X, Xiao H, Ren J, Zhang FR, Liu ZS (2020) Clinical features of severe pediatric patients with coronavirus disease 2019 in Wuhan: a single center's observational study. World J Pediatr. https://doi.org/10.1007/s12519-020-00354-4

20. Xu Y, Li X, Zhu B, Liang H, Fang C, Gong Y, Guo Q, Sun X, Zhao D, Shen J, Zhang H, Liu H, Xia H, Tang J, Zhang K, Gong S (2020) Characteristics of pediatric SARS-CoV-2 infection and potential evidence for persistent fecal viral shedding. Nat Med 26:502-505. https://doi.org/10.1038/s41591-020-0817-4

21. Chidini G, Villa C, Calderini E, De Luca D (2020) SARS-CoV-2 infection in a pediatric department in Milan: a logistic rather than a clinical emergency. Pediatr Infect Dis J in press

22. Jones VG, Mills M, Suarez D et al (2020) COVID-19 and Kawasaki disease: novel virus and novel case. Hosp Pediatr. https://doi.org/10.1542/hpeds.2020-0123

23. Rasmussen SA, Smulian JC, Lednicky JA, Wen TS, Jamieson DJ (2020) Coronavirus disease 2019 (COVID-19) and pregnancy: what obstetricians need to know. Am J Obstet Gynecol 222:415426. https://doi.org/10.1016/j.ajog.2020.02.017

24. Chen H, Guo J, Wang C, Luo F, Yu X, Zhang W, Li J, Zhao D, Xu D, Gong Q, Liao J, Yang H, Hou W, Zhang Y (2020) Clinical characteristics and intrauterine vertical transmission potential of COVID-19 infection in nine pregnant women: a retrospective review of medical records. Lancet 395:809-815. https://doi.org/10. 1016/S0140-6736(20)30360-3

25. Zeng H, Xu C, Fan J, Tang Y, Deng Q, Zhang W, Long X (2020) Antibodies in infants born to mothers with COVID-19 pneumonia. JAMA. https://doi.org/10.1001/jama.2020.4861

26. Dong L, Tian J, He S, Zhu C, Wang J, Liu C, Yang J (2020) Possible vertical transmission of SARS-CoV-2 from an infected mother to her newborn. JAMA. https://doi.org/10.1001/jama. 2020.4621

27. Hu X, Gao J, Luo X, Feng L, Liu W, Chen J, Benachi A, de Luca D, Chen L (2020) Severe acute respiratory syndrome coronavirus 2 (SARS-CoV-2) vertical transmission in neonates born to mothers with coronavirus disease 2019 (COVID-19) pneumonia. Obstet Gynecol. https://doi.org/10.1097/AOG.0000000000003926

28. Zeng L, Xia S, Yuan W, Yan K, Xiao F, Shao J, Zhou W (2020) Neonatal early-onset infection with SARS-CoV-2 in 33 neonates born to mothers with COVID-19 in Wuhan, China. JAMA Pediatr. https://doi.org/10.1001/jamapediatrics.2020.0878

29. Xie X, Zhong Z, Zhao W, Zheng C, Wang F, Liu J (2020) Chest CT for typical 2019-nCoV pneumonia: relationship to negative RTPCR testing. Radiology 200343:200343. https://doi.org/10.1148/ radiol.2020200343

30. National Health Commission of China (2020) New coronavirus pneumonia prevention and control program (4th edn). http:// www.gov.cn/zhengce/zhengceku/2020-01/28/5472673/files/ 0f96c10cc09d4d36a6f9a9f0b42d972b.pdf (in Chinese) [accessed on Mar 1st, 2020]

31. Chen D, Yang H, Cao Y, Cheng W, Duan T, Fan C, Fan S, Feng L, Gao Y, He F, He J, Hu Y, Jiang Y, Li Y, Li J, Li X, Li X, Lin K, Liu
C, Liu J, Liu X, Pan X, Pang Q, Pu M, Qi H, Shi C, Sun Y, Sun J, Wang X, Wang Y, Wang Z, Wang Z, Wang C, Wu S, Xin H, Yan J, Zhao Y, Zheng J, Zhou Y, Zou L, Zeng Y, Zhang Y, Guan X (2020) Expert consensus for managing pregnant women and neonates born to mothers with suspected or confirmed novel coronavirus (COVID-19) infection. Int J Gynecol Obstet 149:130-136. https://doi.org/10.1002/ijgo.13146

32. Lu R, Zhao X, Li J, Niu P, Yang B, Wu H, Wang W, Song H, Huang B, Zhu N, Bi Y, Ma X, Zhan F, Wang L, Hu T, Zhou H, Hu Z, Zhou W, Zhao L, Chen J, Meng Y, Wang J, Lin Y, Yuan J, Xie Z, Ma J, Liu WJ, Wang D, Xu W, Holmes EC, Gao GF, Wu G, Chen W, Shi W, Tan W (2020) Genomic characterisation and epidemiology of 2019 novel coronavirus: implications for virus origins and receptor binding. Lancet 395:565-574. https://doi.org/10. 1016/S0140-6736(20)30251-8

33. van Doremalen N, Bushmaker T, Karesh WB, Munster VJ (2014) Stability of Middle East respiratory syndrome coronavirus in milk. Emerg Infect Dis 20:1263-1264. https://doi.org/10.3201/eid2007. 140500

34. Keyaerts E, Li S, Vijgen L, Rysman E, Verbeeck J, van Ranst M, Maes P (2009) Antiviral activity of chloroquine against human coronavirus OC43 infection in newborn mice. Antimicrob Agents Chemother 53:3416-3421. https://doi.org/10.1128/AAC.01509-08

35. Langel SN, Wang Q, Vlasova AN, Saif LJ (2020) Host factors affecting generation of immunity against porcine epidemic diarrhea virus in pregnant and lactating swine and passive protection of neonates. Pathogens 9:130. https://doi.org/10.3390/ pathogens 9020130

36. Decaro N, Mari V, Desario C, Campolo M, Elia G, Martella V, Greco G, Cirone F, Colaianni ML, Cordioli P, Buonavoglia C (2008) Severe outbreak of bovine coronavirus infection in dairy cattle during the warmer season. Vet Microbiol 126:30-39. https://doi.org/10.1016/j.vetmic.2007.06.024

37. Henry BM, Lippi G, Plebani M (2020) Laboratory abnormalities in children with novel coronavirus disease 2019. Clin Chem Lab Med (CCLM) 0. https://doi.org/10.1515/cclm-2020-0272

38. Sheridan C (2020) Fast, portable tests come online to curb coronavirus pandemic. Nat Biotechnol 38:515-518. https://doi.org/10. 1038/d41587-020-00010-2

39. On behalf of Respiratory Section of the European Society for Pediatric Neonatal Intensive Care (ESPNIC), De Luca D, Piastra $\mathrm{M}$ et al (2013) The use of the Berlin definition for acute respiratory distress syndrome during infancy and early childhood: multicenter evaluation and expert consensus. Intensive Care Med 39:20832091. https://doi.org/10.1007/s00134-013-3110-x

40. Khemani RG, Smith LS, Zimmerman JJ, Erickson S (2015) Pediatric acute respiratory distress syndrome: definition, incidence, and epidemiology. Pediatr Crit Care Med 16:S23-S40. https://doi. org/10.1097/PCC.0000000000000432

41. De Luca D, van Kaam AH, Tingay DG et al (2017) The Montreux definition of neonatal ARDS: biological and clinical background behind the description of a new entity. Lancet Respir Med 5:657666. https://doi.org/10.1016/S2213-2600(17)30214-X

42. Villar J, Ferrando C, Martínez D, Ambrós A, Muñoz T, Soler JA, Aguilar G, Alba F, González-Higueras E, Conesa LA, MartínRodríguez C, Díaz-Domínguez FJ, Serna-Grande P, Rivas R, Ferreres J, Belda J, Capilla L, Tallet A, Añón JM, Fernández RL, González-Martín JM, Aguilar G, Alba F, Álvarez J, Ambrós A, Añón JM, Asensio MJ, Belda J, Blanco J, Blasco M, Cachafeiro L, del Campo R, Capilla L, Carbonell JA, Carbonell N, Cariñena A, Carriedo D, Chico M, Conesa LA, Corpas R, Cuervo J, DíazDomínguez FJ, Domínguez-Antelo C, Fernández L, Fernández RL, Ferrando C, Ferreres J, Gamboa E, González-Higueras E, González-Luengo RI, González-Martín JM, Martínez D, MartínRodríguez C, Muñoz T, Ortiz Díaz-Miguel R, Pérez-González R, Prieto AM, Prieto I, Rivas R, Rojas-Viguera L, Romera MA, 
Sánchez-Ballesteros J, Segura JM, Serna-Grande P, Serrano A, Solano R, Soler JA, Soro M, Tallet A, Villar J (2020) Dexamethasone treatment for the acute respiratory distress syndrome: a multicentre, randomised controlled trial. Lancet Respir Med 8:267-276. https://doi.org/10.1016/S2213-2600(19)30417-5

43. on behalf of the section Respiratory Failure of the European Society for Paediatric and Neonatal Intensive Care, Kneyber MCJ, de Luca D et al (2017) Recommendations for mechanical ventilation of critically ill children from the Paediatric Mechanical Ventilation Consensus Conference (PEMVECC). Intensive Care Med 43: 1764-1780. https://doi.org/10.1007/s00134-017-4920-z

44. The Pediatric Acute Lung Injury Consensus Conference Group (2015) Pediatric acute respiratory distress syndrome: consensus recommendations from the Pediatric Acute Lung Injury Consensus Conference*. Pediatr Crit Care Med 16:428-439. https://doi.org/10.1097/PCC.0000000000000350
45. Ludvigsson JF (2020) Systematic review of COVID-19 in children show milder cases and a better prognosis than adults. Acta Paediatr 109:1088-1095. https://doi.org/10.1111/apa.15270

46. Vandenbroucke JP, von Elm E, Altman DG et al (2007) Strengthening the Reporting of Observational Studies in Epidemiology (STROBE): explanation and elaboration. Ann Intern Med 147:W163-W194

47. De Luca D, Harrison DA, Peters MJ (2018) 'Lumping or splitting' in paediatric acute respiratory distress syndrome (PARDS). Intensive Care Med 44:1548-1550

Publisher's note Springer Nature remains neutral with regard to jurisdictional claims in published maps and institutional affiliations. 